--مجلة علوم الرافدين، المجلد 27، العدد 4 / عدد خاص بالمؤتمر العلمي الثالث لعلوم الحياة، ص 53-63، 2018---

فصل المركبات البروتينية من ثمار نبات الهيل Elettaria cardamomum وتقدير اوزانها الجزيئية

$$
\text { ناهدة سعيد حمودي الجلبي }
$$

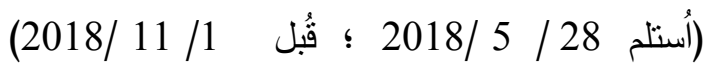

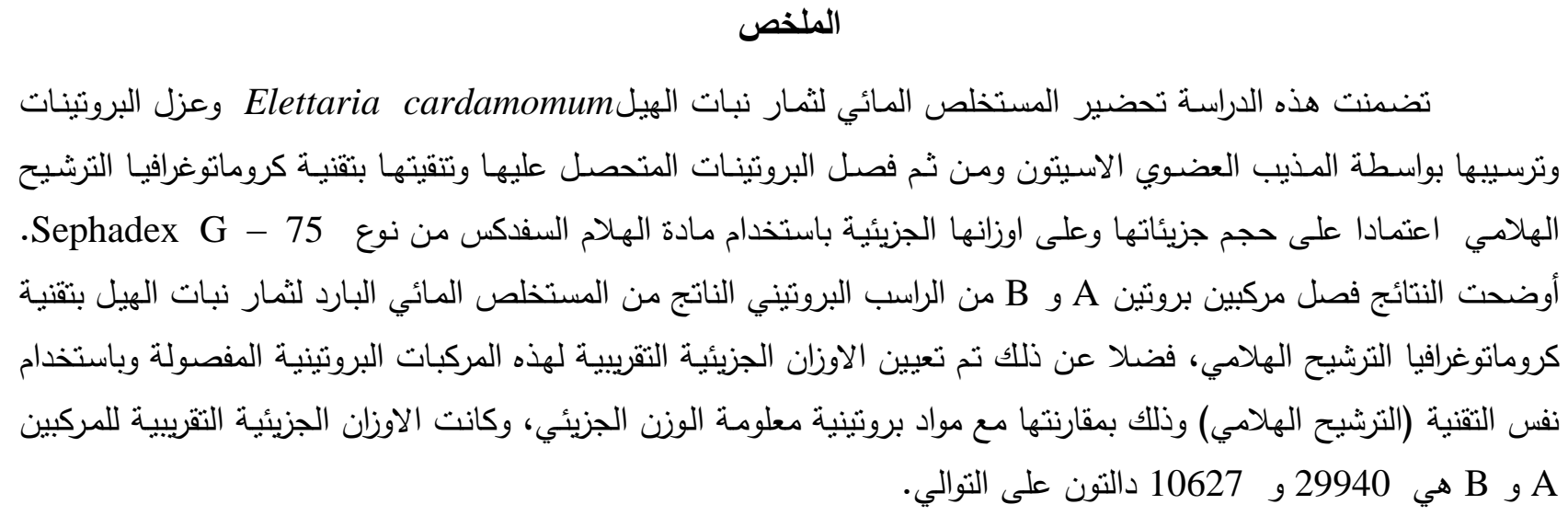

تضمنت هذه الدراسة تحضير المستخلص المائي لثمار نبات الهيلElettaria cardamomum وعزل البروتينات

وترسيبها بواسطة المذيب العضوي الاسيتون ومن ثم فصل البروتينـات المتحصل عليها وتتقيتها بتقنية كروماتوغرافيا الترشيح الهلامي اعتمادا على حجم جزيئاتها وعلى اوزانها الجزيئية باستخدام مادة الهلام السفدكس من نوع 75 - Sephadex G أوضحت النتائج فصل مركبين بروتين A و B من الراسب البروتيني الناتج من المستخلص المائي البارد لنمار نبات الهيل بتقنية كروماتوغرافيا الترشيح الهلامي، فضلا عن ذلك تم تعيين الاوزان الجزيئية التقريبية لهذه المركبات البروتينية المفصولة وباستخدام نفس الثقنية (الترشيح الهلامي) وذلك بمقارنتها مع مواد بروتينية معلومة الوزن الجزيئي، وكانت الاوزان الجزيئية التقريبية للمركبين A و B هي 29940 و 10627 دالتون على التوالي.

الكلمات الدالة :Elettaria cardamomum ، نبات الهيل، بروتين، الترشيح الهلامي، المستخلص المائي.

\title{
Isolation of Protein Compounds from Elettaria cardamomum Fruits Plant and Determination of their Molecular Weights
}

\author{
Nahida S. Al-Chalabi \\ Rasha H. Al -Juboory \\ Department of Chemistry/College of Education for Pure Science/University of Mosul
}

\begin{abstract}
This study included preparation of aqueous extract for fruits of Elettaria cardamomum plant, isolation of their proteins and precipitation takes place by using acetone. The precipitate of the isolated proteins were purified using gel filtration chromatography depending on the volume of their molecules (proteins) and their molecular weights by a gel of Sephadex $G-75$. The results were shown that there are two protein compounds A and B isolated from the protein precipitate resulted from cold aqueous extract for this plant by gel filtration chromatography. Then the molecular weight was determined for these compounds isolated using the same techniques (gel filtration) by comparison these compounds with proteins known molecular weights. The approximate molecular weight of two compounds A and B are 29940, 10627 Dalton respectively.
\end{abstract}

Keywords: Elettaria cardamomum, protein, gel filtration, aqueous extract.

\section{المقدمة}

يعد الهيل من النباتات الطبية والعطرية، النبات الطبي مصطلح يقصد به النبات الذي يحوي فوائد دوائية مؤثرة ويستعمل في مجال الطب وقد حل هذا التعريف محل كلمة (عشب) التي أطلقت منذ قديم الأزمنة على أب نبات يستعمل في المداواة العشبية 
وذللك قبل ان تعرف الفوائد المؤثرة (يحيى، 2003). فالإنسان منذ القدم تعرف على الكثير من النباتات والاعشاب الطبيعية التي

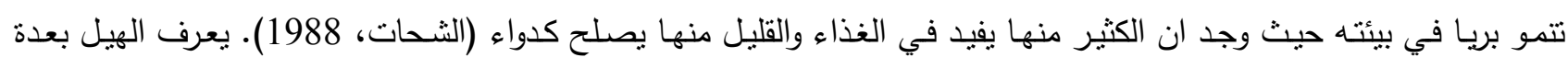
تسميات منها حب الهال، قاقلة، فول مالابار ، سرنديب، ويعود الى فصيلة القاقليات Amonaceae (يحيى، 2003) ويطلق عليه

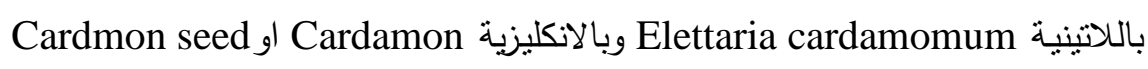

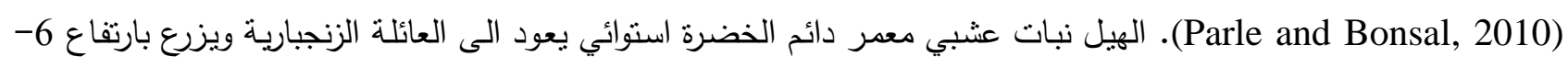
12م وسيقانه رايزومية متفرعة (Purseglove et al.,1981) نكون الثمار بشكل شفاف (محافظ) مخضوضرة سمراء بيضوية او

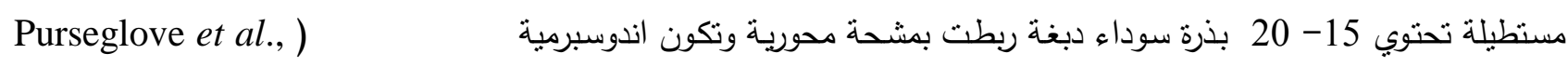

يوجد الهيل مزروعاً او برياً وينمو في المناطق الرطبة القريبة من خط الاستواء (يحيى،2003) وتعد الهند الموطن الاصلي لهذا النبات وله قيمة تجارية عظيمة (يحيى، Bartle andSpechy, 2010; 2003 وهناك إثارات إلى استخدامه من قبل البابليين

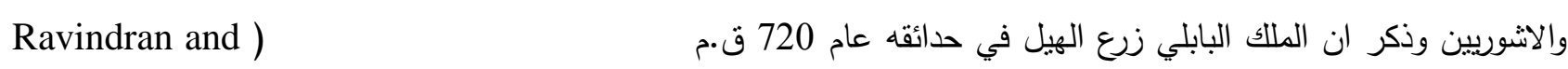
(Modhusoodamn, 2004 العظيم، واليوم تتوجه الولايات المتحدة في شراء اغلب بذور الهيل من غواتيمالا بسبب ولع الهنود في استهلاك معظم ما ينتجه

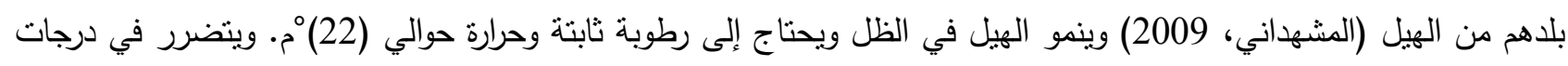
الحرارة المنخفنة (10)ْم. وينمو على ارتفاع 5 أقدام في غابات الأمطار الاستوائية ويحتاج مدارات دافئة لتكوين البذور

.(Christman, 2006)

يحتوي الهيل زيتا عطريا ومواد دسمة اخرى ومواد معدنية اهمها الكالسيوم، ومواد مشهية وهاضمة (يحيى، 2003) ومن

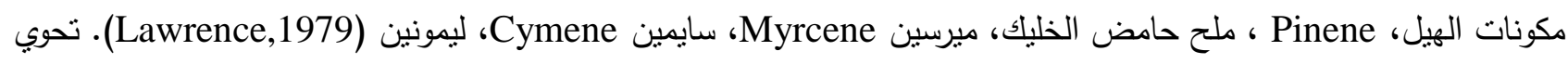

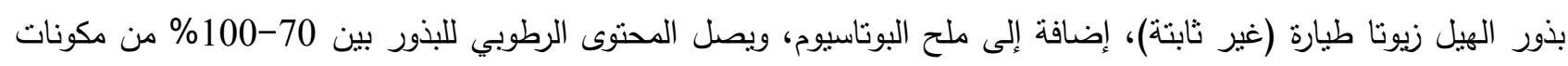

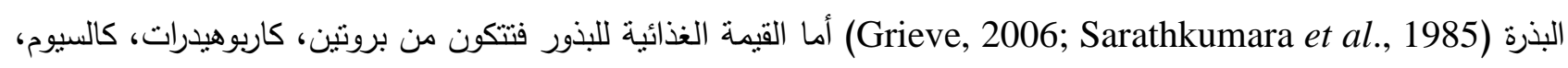

راييوفلافين، ونياسين (Christman, 2006).

لنبات الهيل قيمة طبية عالية اذ بستخدم كمكون طبيعي لعلاج الأسنان وذلك من خلال استخدامه كمجون ولغرغرة الاسنان واللثة (يحيى، Nambiar and Raveendran, 2008 ويستخدم الهيل كتابل حيث يعرف الهيل بملك التوابل ويعد من الفاكهة المجففة ويستخدم زيت الهيل في الغذاء والعطارة وفي الصناعات الدوائية وطارد للغازات ويدخل في صناعة المواد الغذائية وفي المخلات ولتحسين النكهة يستخدم في الثوربات المعلبة (Purseglove et al.,1981) كذلك يستخدم ضد البكتريا التي تسبب قترة الراس وحب الثباب (Daris and Fraser,1992) ويستعمل في حالة التشنج ومضادا للغنيان والقيء، مقشعا ومضادا لسلس البول عند الصغار (بيلة الفراش Enuresis) ويستعمل مغليه مع البابونج او الزعتر البري غسولا للاكزما النازة، وغرغرة الفم وفركآ لفروة الرأس في النخالية (القشرة) ومضغا في حالة نخر الاسنان (يحيى،2003) وايضا يستخدم لتخفيف ادمان

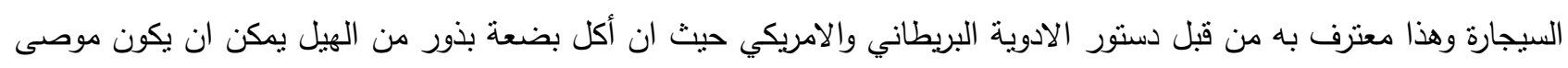

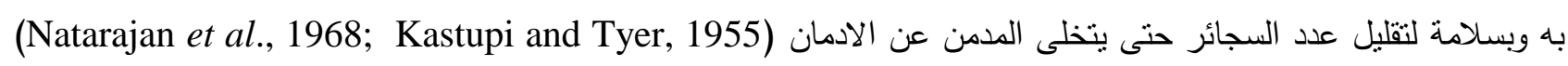
ويتلاءم طعم الهيل الى حد ما مع الطعام البحري وذلك لصفاته الحامضية ويستخدم الهيل المطحون كعنصر منكه للقهوة العربية (المشهداني، 2009) 
المواد وطرائق العمل

تحضير المستخلص المائي لثمار نبات الهيل

Preparation of the aqueous extract of Elettaria cardamomum fruit of the plant وزن (100) غرام من حبات الهيل التي نم الحصول عليها من السوق المحلي، وطحنت باستخدام الطاحونة الكهربائية

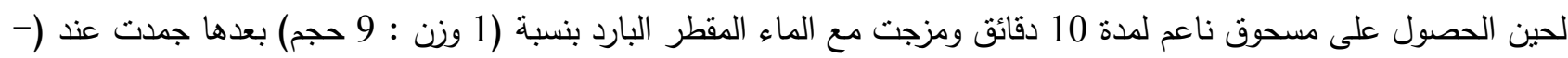
20) ثم ثم تركت تذوب عند درجة حرارة الغرفة. كررت العملية سبع مرات وبعدها استخدم جهاز الامواج فوق الصوتية (Ultrasonic)

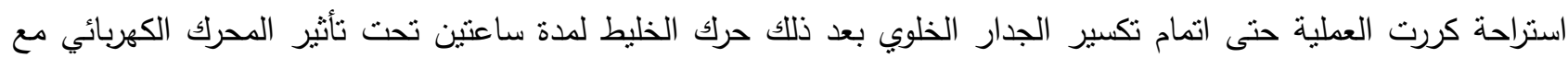

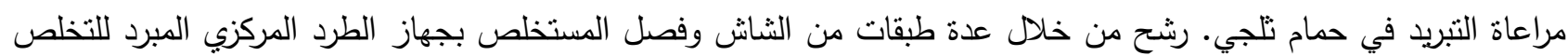
من المواد غير الذائبة لمدة (20) دقيقة بسرعة (33520×g ) للحصول على راشح رائق (عبد المانع ، 2002) وقيس حجم الراشح (606) مل. وقدرت كمية البروتين له حسب طريقة لاوري المحورة (Schacterle and Pollack, 1973) وقلص حجم

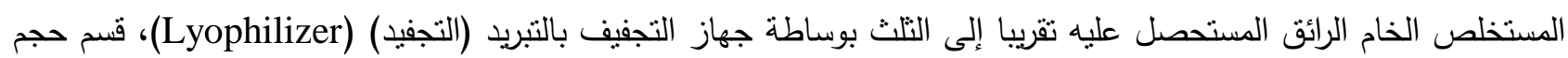
هذا المستخلص الخام المستحصل عليه بعد التجفيد الى قسمين، الاول يكون معدا لاجراء العملية اللاحقة وهي الترسيب بالاسيتون والقسم الاخر جفف بتقنية التجفيد لحين الحصول على مسحوق منه حيث حفظ في انبوبة محكمة الغطاء وفي المجدة (-20)ْم الخداء لحين استخدامه. عزل البروتينات وترسيبها بوساطة المذيب العضوي Isolation and organic solvent precipitation of the proteins

أضيف الأسيتون البارد إلى المستخلص بنسبة (3:2) حجم:حجم ببطء مع التحريك المستمر عند درجة حرارة (4م) ثم

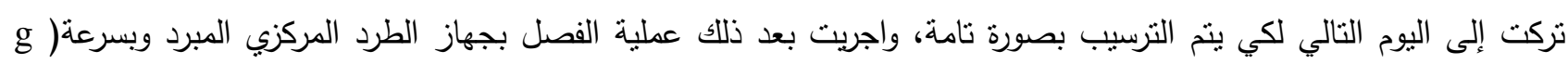

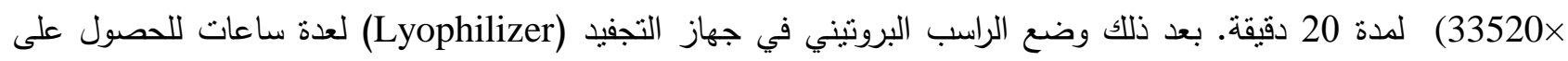
المادة بشكل مسحوق، وحفظ في انبوبة محكمة الغطاء في المجمدة لحين اجراء عملية تجزئته بتقنية كروموتوغرافيا الترشيح

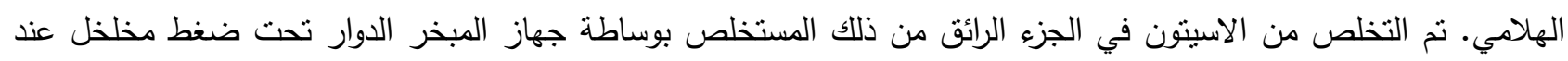
درجة (40)م وتم التاكد من عدم وجود البروتين في الجزء الرائق وذلك بتقدير كمية البروتين بطريقة لاوري المحورة (Schacterle and Pollack , 1973) المادة بشكل مسحوق اطلق عليها المواد غير البروتينية. حفظت بعد ذلك في المجمدة في انابيب محكمة الغطاء.

\section{Partition of protein by Gel-filtration chromatography technique}

تجزئة البروتين بتقتية كروماتوغرافيا الترشيح الهلامي Basic principle for technique : المبدأ الأساسي للتقتية تعد تقنية الترشيح الهلامي احدى التقنيات المهمة في مجال الكيمياء الحياتية، وهي احدى الطرق المستخدمة لفصل المركبات منل البروتينات وتتقيتها اعتمادا على حجم جزيئاتها وعلى اوزانها الجزيئية. فالمركبات ذات الاوزان الجئية الجزيئية الكبيرة لاتتفذ

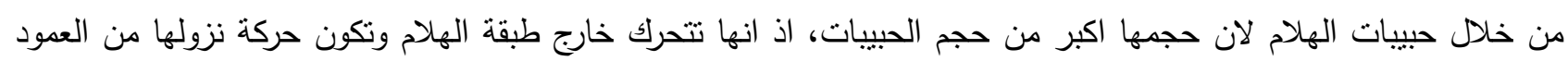
اسرع ، اما المركبات ذات الاوزان الجزيئية الصغيرة (اصغر من حجم ثقوب الهلام) فباستطاعتها الدخول إلى حبيبات الهلام. وبذلك تكون حركة نزولها أبطأ وتترشح أخيرا، بعد ذلك يتم جمع الأجزاء المفصولة من الترشيح الهلامي باستخدام جامع الأجزاء الاوتوماتيكي (Fraction collector). ويقاس حجم المحلول المنظم او الماء المقطر لازاحة كل حزمة بروتينية من عمود 
Stanton, ) الفصل. ويتم التعرف على المواد البروتينية من خلال قراءة شدة الامتصاص عند طول موجي (280) نانوميتز 2003). كما تعد تقنية الترشيح الهلامي طريقة لتقدير الوزن الجزيئي التقريبي للمواد البروتينية المجهولة ( Clark and Switzer 1977,) وذللك من خلال تسقيط حجم الروغان للبروتين المجهول على الرسم البياني الذي يوضنح العلاقة بين حجم الروغان ولوغاريتم الوزن الجزيئي (Anderws, 1965 ; Robyt and White, 1987).

\section{Packing of the column تعبئة عمود الفصل}

استخدمت مادة الهلام السفدكس من نوع 75 (Sephadex G-75) في تعبئة عمود الفصل ذي الأبعاد (120x1.8 120 )

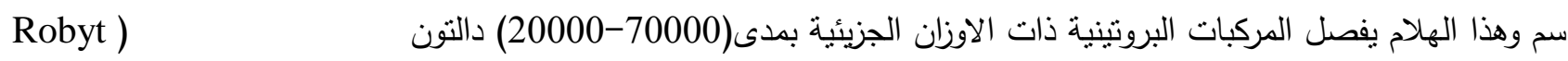
and White, 1987 (and). واعتمادا على حجم العمود الذي يساوي (219) مل. وضعت مادة الهلام إلى ارتفاع (86) سم وذلك

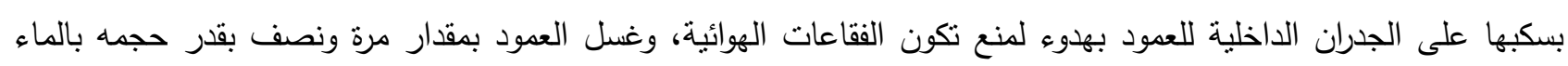
المقطر (Morris and Morris,1976)، وبذلك اصبح العمود جاهزا لإمرار الأنموذج (محلول مادة الراسب البروتينية).

إضافة المادة البروتينية المعزولة من المستخلص المائي البارد لثمار نبات الهيل حضر محلول مركز من المادة البروتينية المعزولة من المستخلص المائي البارد لثمار نبات الهيل والذي تم تقدير كمية الثية

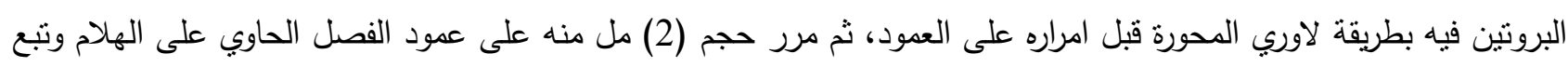

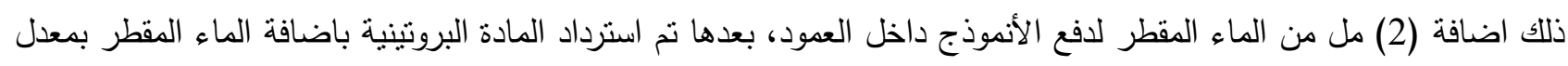
جريان (33.5 مل /ساعة) أي بمعدل 10 دقائق لكل جزء من جامع الاجزاء الاوتوماتيكي الذي يعمل على نظام الدقائق ونم الذاء

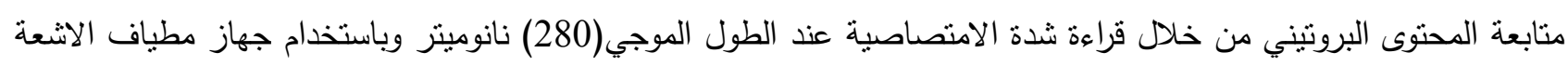
فوق البنفجية والمرئية ثم جمعت كل حزمة ناتجة عن فصل مادة الراسب البروتينية على حدة حسب الرسم البياني للامتصاصية مقابل حجم الروغان، وقدرت كمية البروتين في كل حزمة بطريقة العالم لاوري المحورة، اعيدت عملية الفصل لهذه المادة البرة البروتينية

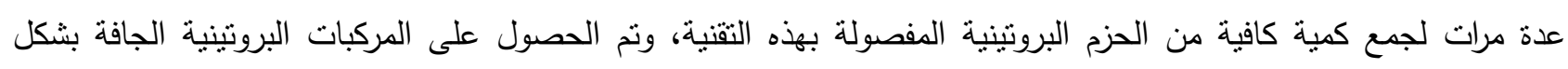

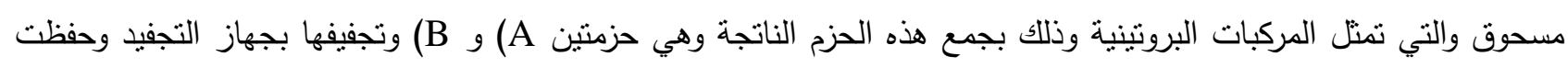

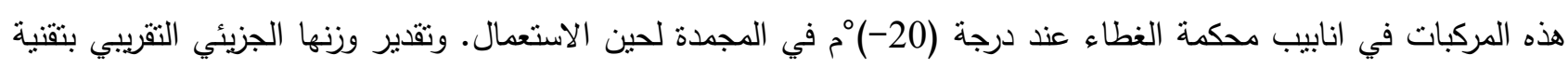
الترشيح الهلامي.

\section{تعيين الوزن الجزيئي التقريبي للمركبات البروتينية المفصولة بتقنية الترشيح الهلامي}

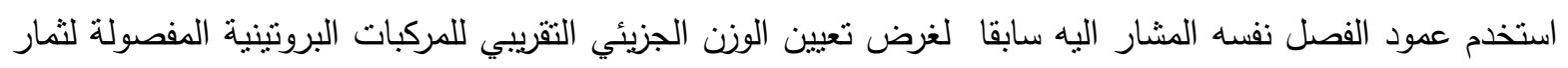

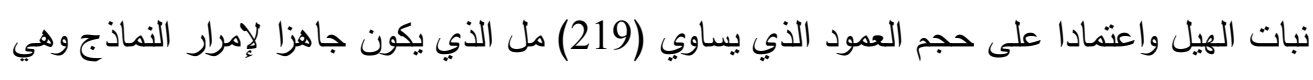
أ المواد القياسية : البات واعياد

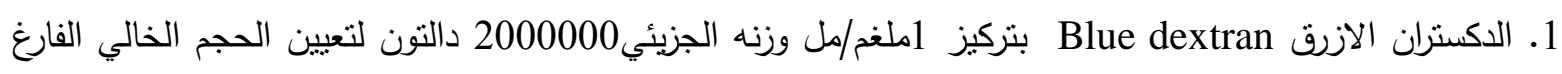

من الحبيبات Vo=void volume. 2. البومين مصل البقر Bovine serum albumin) BSA) بتركيز ملغخ/ مل وزنها الجزيئي 67000 دالتون.

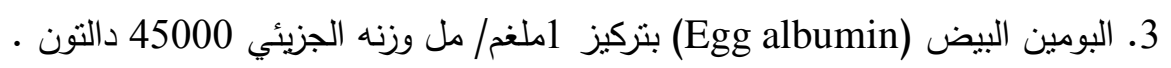

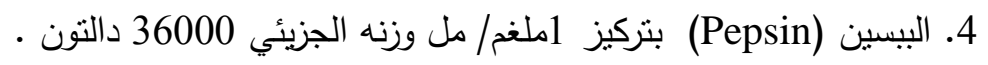


6. التربسين (Trypsin) بتركيز ملغم/ مل وزنه الجزيئي 23000 دالتون.

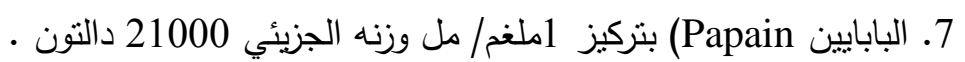

8. الحامض الاميني التربتوفان Tryptophan بتركيز 1ملغ/ مل وزنه الجزيئي 204 دالتون لتعيين الحجم الداخلي

ل للعمود Vi =internal volume

ب/ المركبات البروتينية المفصولة والمجهولة الوزن الجزيئي : تم امرار المواد القياسية والمركبات البروتنية كلا على حدة بحجم (2) مل في عمود الفصل، وتم استردادها ثم حسب الثبات حجم الروغان (قمة الحزمة) لكل من المركبات البروتينية والمواد القياسية بدقة من خلال متابعة المحتوى البروتيني بعدها رسم لوغاريتم الوزن الجزيئي مقابل حجم الروغان لها والذي يستخدم لايجاد الوزن الجزيئي التقريبي المجهول للمركبات البروتينية الدفصولة.

Quantitative determination of proteins التقدير الكمي للبروتينات

Schacterle and ( عينت كمية البروتينات في المستخلص المستحصل عليه باستخدام طريقة العالم لاوري المحورة Pollack, 1973 ( استخدم البومين مصل البقر (Bovine serum albumin -BSA) بتركيز املغم/ مل بوصفه محلولاً قياسياً له معامل امتصاصية مولارية Extinction coefficient يساوي (0.67) (Holme and Peck, 1988). والثكل (1) يوضح

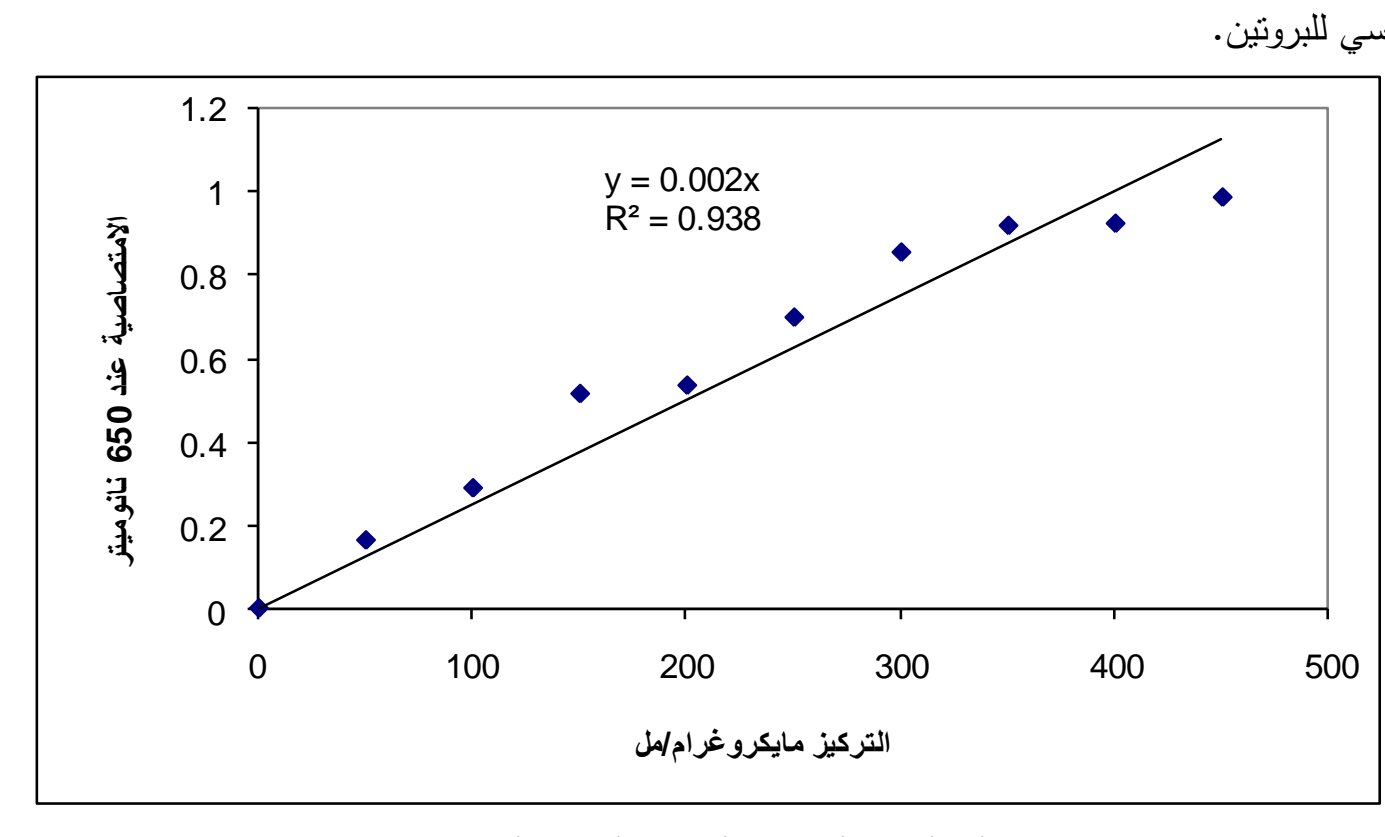

الشكل 1: المنحني القياسي لتقدير البروتين

الكثوفات اللونية

Biuret test

كثف بايوريت:

لمعرفة فيما اذا كان المستخلص غير البروتيني خاليا من البروتين، كذلك التأكد من وجود البروتين في المستخلص تم استخدام كثف بايوريت وضع (2) مل من المحلول (المستخلص غير البروتيني) في انبوبة اختبار ثم أضيف إليه (2) مل من (10\%)

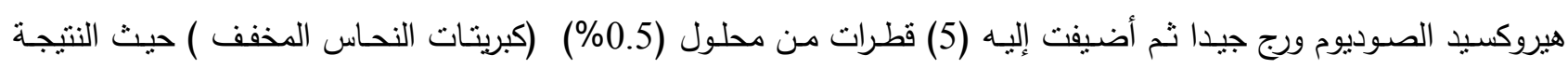
الموجبة ملاحظة ظهور اللون البنفسي مما يدل على وجود البروتين أما النتيجة السالبة فهي عدم ظهور اللون البهن البنفجي. 


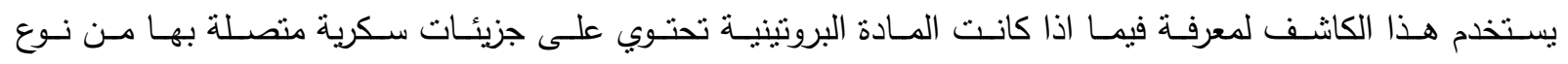
(Glycoprotein) البروتيني المراد الكثف عنه، ورج المزيج جيدا ثم اضيف (2) مل من حامض الكبريتيك المركز بشكل قطرات إلى جدران الانبوبة الداخلية بهدوء مع ملاحظة تكون الحلقة البنفسجية مابين الطبقتين.

\section{النتائج والمناقشة}

\section{Preparation of homogenous extract}

مستخلص نبات الهيل وفصل بروتيناته وتقديرها تحضير المستخلص المائي المتجانس

استخلصت المواد البروتينية الموجودة داخل خلايا ثمار نبات الهيل باستخدام التجميد والتذويب (and Thawing)

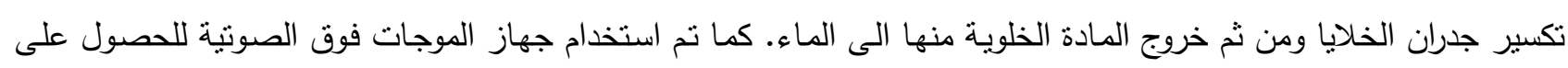

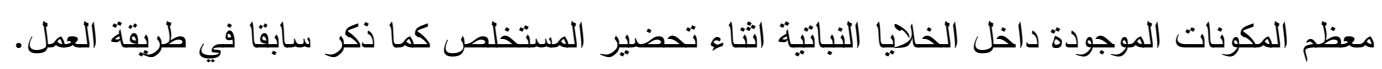

\section{Precipitation of proteins by organic solvents}

ترسيب البروتينات باستخدام المذيب العضوي

تترسب البروتينات في المحاليل المائية بوسـاطة المذيبات العضـوية مثل الاسيتون والكحول حيث تعدل كل مـن هذه

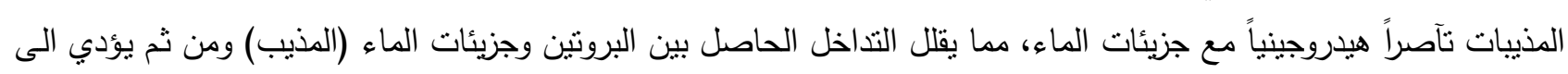

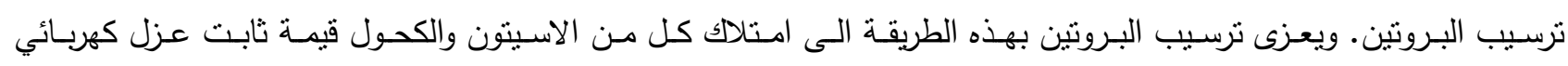
Dielectric constant الثحنات المتعاكسة مما يقلل درجة تأين مجاميع R للاحماض الامينية، وهذا يسبب تكتل جزيئات البروتين وترسبه (ال فليح، 2000) والمعادلة الآتية توضح ذلك:

$$
\mathrm{F}=\mathrm{e}_{1}-\mathrm{e}_{2} / \mathrm{Dr}^{2}
$$

$$
\begin{aligned}
& \text { اذ ان F قوة التجاذب بين ايونين لهما شحنات مختلفة } \\
& \text { شحنات الايونات } \\
& \text { ثابت العزل. D } \\
& \text { rer }
\end{aligned}
$$

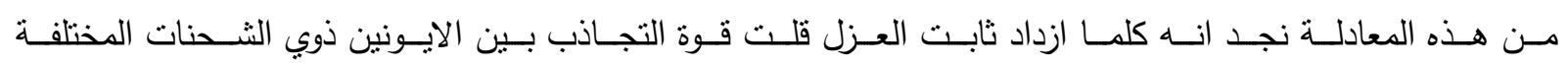

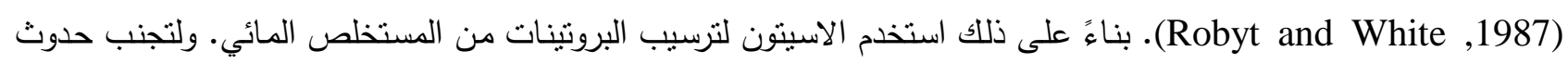
المستخ الناتج من حرارة المزج عند إضـافة المذيب العضوي (الاسيتون) الى المحلول المائي للبروتين استخدم واختير الاسيتون

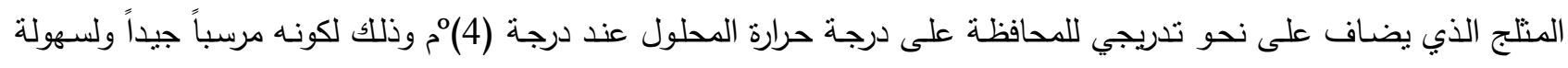
التخلص منه في الدرجات الحرارية المنخفضة. كما وجد ان نسبة المذيب العضوي (V/V 40/60) الى المستخلص تعطي اكبر كمية من البروتين المترسب مobyt)

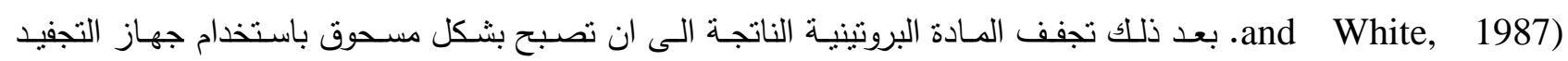


وذللك لمنع تلوثها بالأحياء المجهرية لأنها تعد وسطاً غذائياً جيداً للعديد من الإحياء المجهرية، ومن ثم يحفظ في المجمدة بدرجة (-20) لحين استخدامها في تجارب لاحقة.

تقدير البروتين بطريقة لاوري المحورة والكثوفات اللونية

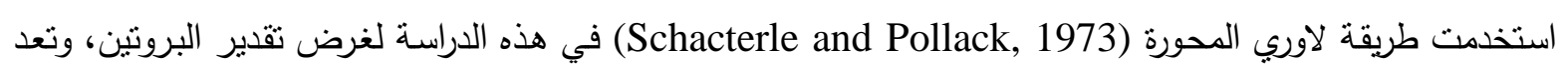

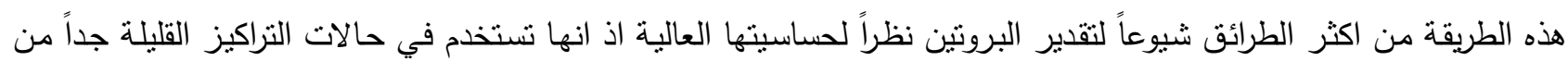
البروتين وهي تعطي ناتجاً بعد 40 دقيقة. تتضمن الطريقة استخدام كاثف فولن في وسط قاعدي الذي يعطي معقداً ازرق اللون

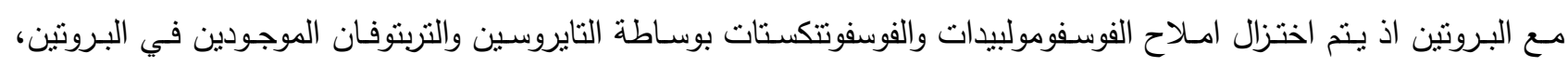

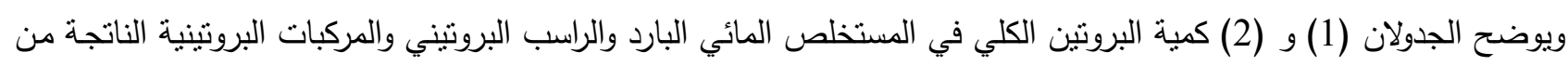
الترشيح الهلامي وكفاءة الترسيب، وبعد اجراء كثف مولش وبايوريت على مادة الراسب البروتينية اعطى كثف مولث نتيجة سلانس سالبة

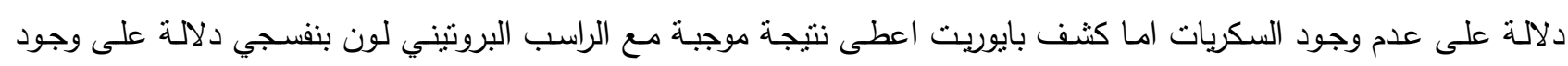
البروتين ونتيجة سالبة مع المستخلص غير البروتيني دلالة على عدم وجود البروتين.

الجدول 1: كمية البروتين الكلي والنسبة المئويـة وكفاعة الترسيب بالاسيتون في المستخلص المـائي الخام البارد لثمار نبات

\begin{tabular}{|c|c|c|c|c|c|c|c|}
\hline & & & & & & & الهيل. \\
\hline كالأسيتون (الترسيب & وزن المحصل عليه & وزن & البروتين في نسبة & كمية البروتين & للمستخلص الكلي & تركيز البروتين & نوع المستخلص \\
\hline 73.65 & 1521 & 50 & 4.13 & 2065.854 & 303 & 6.818 & 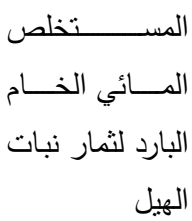 \\
\hline
\end{tabular}

فصل مادة الراسب البروتينية المعزولة من المستخلص المائي البارد لثمار نبات الهيل بتقنية كروماتوغرافيا الترشيح الهلامي

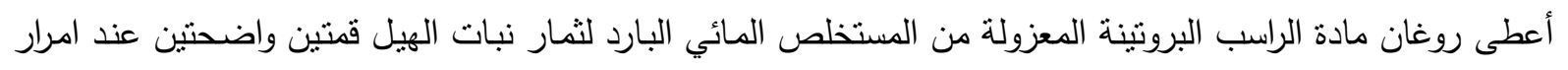

محلولها في عمود الفصل المذكور سابقا في طريقة العمل والمبينة في الثكل (2). 


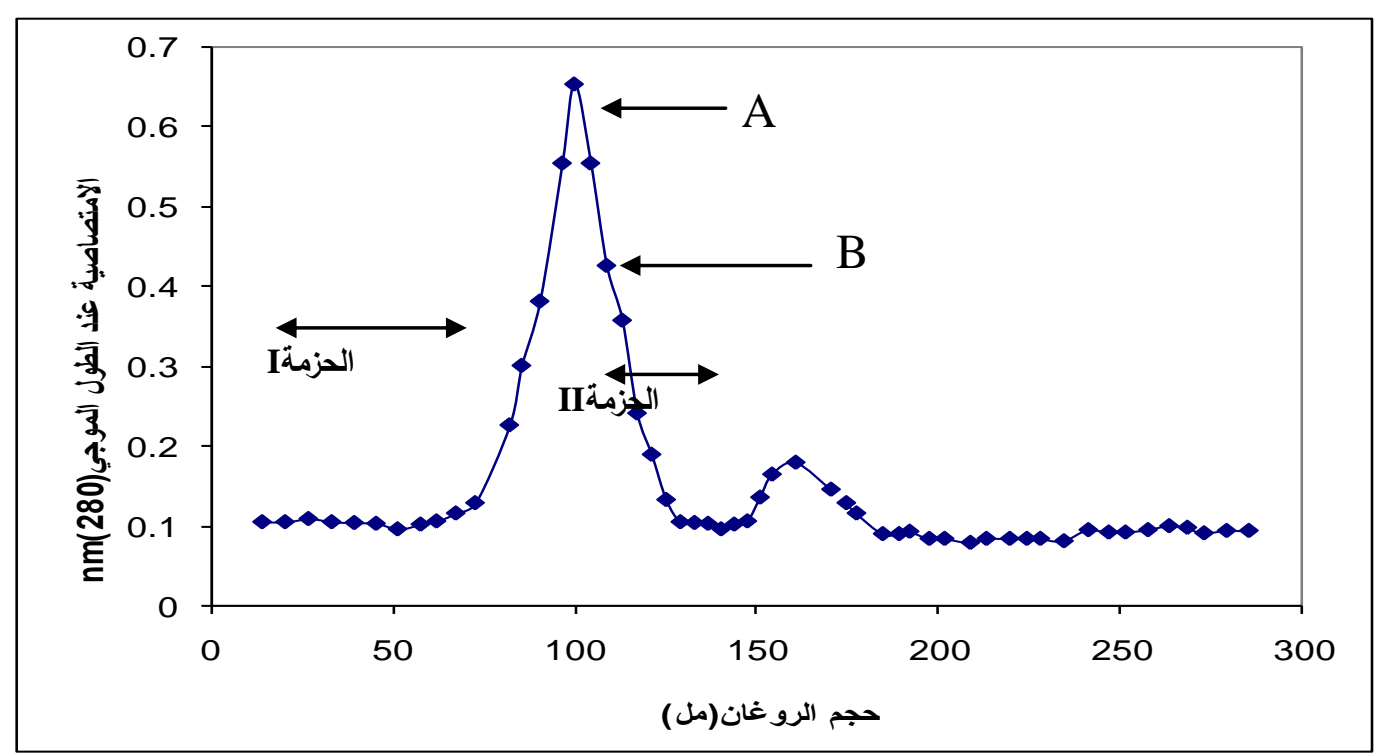

الثكل 2: المظهر الجانبي لروغان الراسب البروتيني المعزول من المستخلص المـائي الخـام البارد لثـار نبات الهيل بتقتية

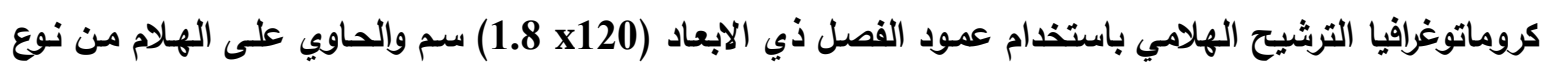

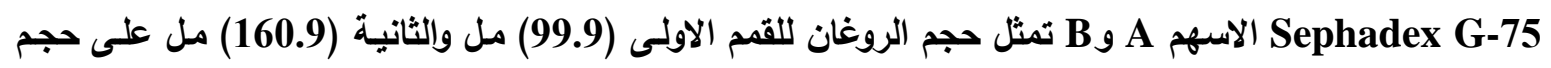
كل جزء (5) مل ويمعدل جريان (33.5 مل/ساعة) للحزم البروتينية المفصولة .

إيجاد كمية البروتين الكلي في مادة الراسب البروتينية للمستخلص المائي الخام البارد لثمار نبات الهيل قبل التمرير في عمود

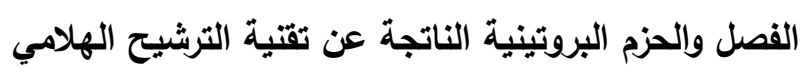

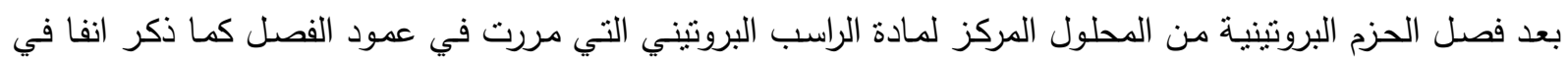

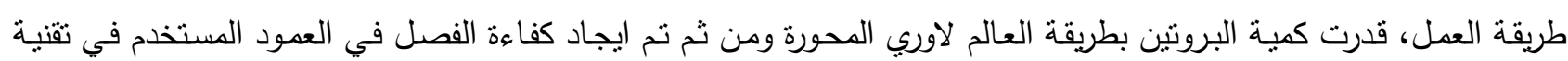

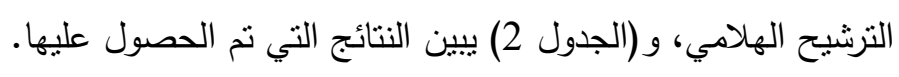

الجدول 2: كمية البروتينات للمحاليل المركزة قبل تمريرها في عمود الفصل والمركبات(الحزم) البروتينية الناتجة من الترشيح

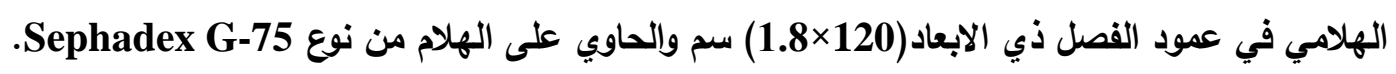

\begin{tabular}{|c|c|c|c|c|c|}
\hline كفاءة & $\begin{array}{l}\text { النئوية } \\
\text { النسبة }\end{array}$ & 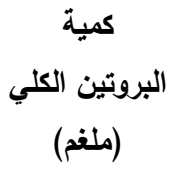 & العجم (الكلي & تركيز البروتين & نوع البروتين \\
\hline \multirow{3}{*}{86.71} & 100 & 11.392 & 2 & 5.696 & 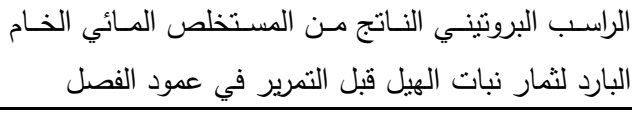 \\
\hline & 66.74 & 7.6037 & 58.49 & 0.130 & من الراسب البروتيني البارد A المفــول بتقنيـة الترشيح الهلامسي \\
\hline & 19.97 & 2.275 & 25 & 0.091 & الراسب البروتيني البارد البرتيني المفول بتقنية الترشيح الهلامي من \\
\hline
\end{tabular}


الأوزان الجزيئية التقريبية للمركبات البروتينية المفصولة

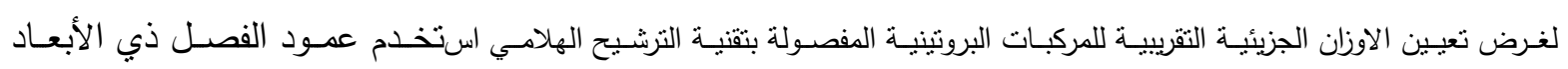

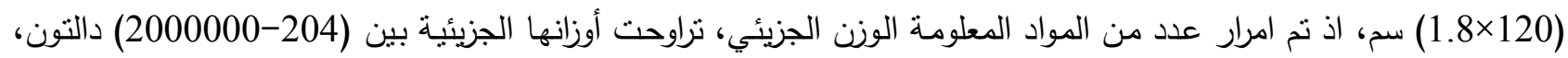
بعد ذللك تم تعيين حجوم الروغان لهذه المواد كما هو مبين في (الجدول 3ن المورد).

الجدول 3: حجم روغان المواد القياسية المعلومة الوزن الجزيئي

\begin{tabular}{|c|c|c|c|c|}
\hline حجم الروغان(سم²) & الوزن الجزيئي & المادة & & ل لتسلسل \\
\hline 42 & 2000000 & Blue dextran & الدكستران الازرق & 1 \\
\hline 51 & 67000 & Bovine serum albumin & البومين مصل البقر & 2 \\
\hline 70 & 45000 & Eggs albumin & البومين البيض & 3 \\
\hline 88 & 36000 & Pepsin & ببسين & 4 \\
\hline 118 & 23000 & Trypsin & تريسين & 5 \\
\hline 138 & 21000 & Papain & البابايين & 6 \\
\hline 186 & 5734 & Insulin Hormone & هرمون الانسولين & 7 \\
\hline 235 & 204 & Tryptophan & التربتوفان & 8 \\
\hline
\end{tabular}

وعند رسم حجم الروغان (Elution volume) لكل مادة مقابل لوغارنم الوزن الجزيئي تم الحصول على المنحني القياسي لتقدير الوزن الجزيئي كما هو مبين في الثكل (3) والذي من خلاله يمكن تحديد الوزن الجزيئي التقريبي للمركبات المفصولة.

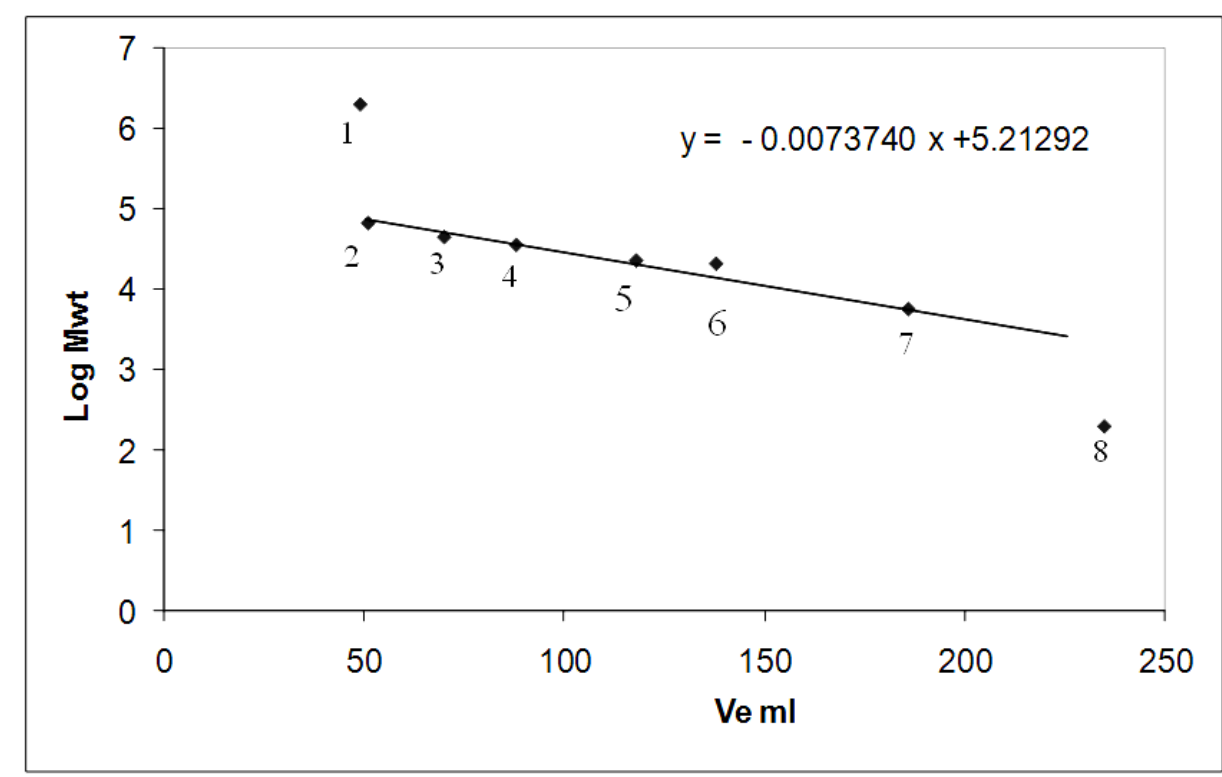

الثكل 3: المنحني القياسي لتقدير الوزن الجزيئي التقريبي للبروتينات

ومن خلال إسقاط حجوم الروغان التي تم الحصول عليها للمركبات البروتينية المفصولة بتقنية الترشيح الهلامي على المنحني

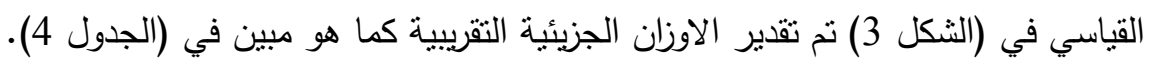




$$
\text { ناهدة سعيد حمودي الجلبي و رشا حسين علي الجبوري }
$$

الجدول 4: الاوزان الجزيئية التقريبية للمركبات البروتينية المفصولة بتقتية الترشيح الهلامي التي تم الحصول عليها

\begin{tabular}{|c|c|c|}
\hline الوزن الجزيئي التقريبي(دالتون) & حجم الروغان(مل) & 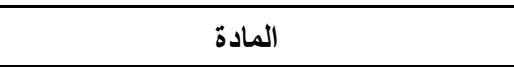 \\
\hline 29940.3 & 99.9 & البرات الهرتيلي للمستخلص المبائي الخام البارد لثمار \\
\hline 10627.8 & 160.9 & البروتيني اللمستخلص المبائي الخام البارد لثمار \\
\hline
\end{tabular}

\section{المصادر العربية}

آل فليح، خولة احمد (2000). "مدخل الى الكيمياء الحياتية". دار الكتب للطباعة والنشر ، الطبعة الثانية، جامعة الموصل، ص ص

الثحات، نصر ابو زيد (1988). "النباتات العطرية ومنتجاتها الزراعية والدوائية". مطبعة جامعة بغداد، بغداد، العراق. ص 15. المشهداني، مفاز خليل حمودي (2009). "النباتات العشبية الطبية استعمالاتها وفوائدها". رقم الايداع بدار الكتب والوثائق ببغداد مئه

$$
\text { .869. ص 3، } 103
$$

عبد المانع، خالد صالح عمر (2002). " عزل البروتينات والاجزاء غير البروتينية من نباتي السبحبح وخس الزيت ودراسة تأثيرها على مستوى السكر في الدم". رسالة ماجستير ، كلية التربية، جامعة الموصل، الموصل، العراق.

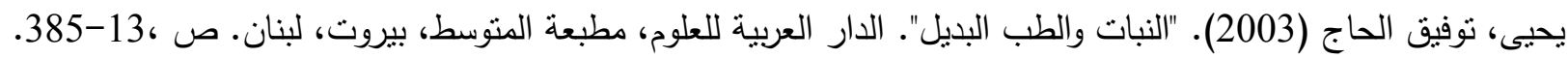

\section{المصادر الأجنبية}

Andrews, P. (1965). The Gel filtration behaviour of protein related to their molecular weight over a wide range. Biochem. J., 96, 596-606.

Bartle, E.M.; Spechy, D.S. (2010). Evidence for the involvement of Glo Bos A-like, in duplications and expression diver game in the evolution of flaval morphology in zingiberales. $J$. Comp, New phyto., Chem. Abst. 94720.

Christman, S. (2006). "Flavidata: Elettaria cardamomum". www. flavidata.com. LC. Tallahasse flavide. A., pp.2-3.

Clark, J.M.; Switzer, R.L. (1977). "Experimental Biochemistry". San Francisco, USA, pp. 73-77.

Daris, L.; Franser, L. (1992)."Fight varieties with cardamom". Health. 6(2), 8.

Grieve, M. (2006). Cardamons Botanical: Elettaria cardamomum Maton Amodern Herbal. Ind. J., $1-4$.

Holme, D.J.; Peck, H. (1988). "Analytical Biochemistry". John Wiley and Sons, Inc , New York, pp. 86-88.

Kastupi, T.R.; Tyer, B.H. (1955). Fixed oil from Elettaria Cardamomum seeds. J. Indian. Inst. Sci., 37 A,106.

Lawrence, B.M. (1979). "Major Tropical Spices-cardamom (Elettaria cardamoum) in Essential Oils". Allured publ., whcat. on, Ш , 104.

Morris, C.J.; Morris, P. (1976). "Separation Method in Biochemistry". $2^{\text {nd }}$ ed., pitman publishing, $442 \mathrm{p}$.

Nambiar, R.; Raveendran, K. (2008). Indigenous medicinal plants scripted in amarakosam. Am .J. Bot., 1(3), 68-72. 
Natarajan, P.; Kuppnswawy, S.; Krishnamurthy, M.N. (1968). A study on the maturity regional variation and retention of green colour of cardamoum. J. Food Sci. Technol., 5, 65.

Parle, M.; Bonsal, N. (2010). Antiamensic activity of an ayurvedic formulation chyarran prash in mice. CAM, 1-10.

Pureseglove, J.W.; Brewn, E.G.; Green, C.L.; Robbins, S.R. (1981). "Biochemistry of Zingiberis Rhizoma Species". Vol. 2 . Longman. Inc. New York.

Ravindran, P.N.; Madhusoodana, K.J. (2004). "Cardamoum the Genus Elettaria". CPC press. London and New York. pp.3-90.

Robyt, F.J.; White, J.B. (1987). "Biochemical Techniques, Theory and Practice". Brookes/Cole publishing company, Monterey, California, pp. 115-118.

Sarathkumara, S.J.; Paciasothy, E.V.; Janz, E.R. (1985). Some studies on the effect of maturity and storage on the chlorophy11 content and essential Oils of the cardamomum fruit (Elettaria cardamomum Maton). J. Sci. Food and Agri., 36(6), 491-198.

Schacterle, G.R.; Pollack, J.K. (1973). A simplified method for the quantitative assay of small amount of protein in biological materials. Anal. Biochem., 51, 654-655.

Stanton, P. (2003). "Gel Filtration Chromatography". Human a press., 251, pp. 55-74. 